\title{
LOS CONTRATOS INTERNACIONALES INTERVINIENTES EN EL MERCADO ASEGURADOR EN EL ÁMBITO DEL DERECHO INTERNACIONAL PRIVADO DE LA UNIÓN EUROPEA
}

\author{
INTERNATIONAL AGREEMENTS INVOLVE IN THE INSURANCE \\ MARKET IN THE FRAME OF THE EUROPEAN PRIVATE \\ INTERNATIONAL LAW
}

\author{
Hilda Aguilar Grieder \\ Profesora Titular de Derecho Internacional Privado \\ Universidad de Huelva \\ ORCID ID: 0000-0002-3138-8904
}

Recibido: 15.06.2020 / Aceptado: 01.07.2020

DOI: https://doi.org/https://doi.org/10.20318/cdt.2020.5601

\begin{abstract}
Resumen: El presente estudio analiza el tratamiento, en el ámbito del Derecho internacional privado europeo, de los contratos internacionales intervinientes en el mercado asegurador desde el prisma del sector del Derecho aplicable; así como los efectos que tal tratamiento provoca en el seno del mercado interior y los medios disponibles para solventarlos.

Palabras clave: Derecho internacional privado de la Unión Europea, contratación internacional, contratos internacionales intervinientes en el mercado asegurador, fragmentación en las soluciones conflictuales y distorsiones sobre el mercado interior.
\end{abstract}

Abstract: This study analyses the law applicable treatment to the contracts involve in the insurance market. The fragmentation of the conflict of law solutions relating to the contracts involve in the insurance market led to effects in the internal market. It is necessary to find a solution to that problems.

Keywords: European Private International Law, international agreements, international contracts involve in the insurance market, fragmentation of the conflict of law solutions, effects to the internal market.

Sumario: I. Los contratos internacionales intervinientes en el mercado asegurador: cuestiones clave. II. Coexistencia de la Directiva sobre la distribución de seguros de 2016 con el Derecho internacional privado europeo. 1. Planteamiento general. 2. Transposición al ordenamiento jurídico español de la Directiva sobre la distribución de seguros de 2016 por la vía del reciente Real DecretoLey 3/2020. III. Dispersión conflictual en el seno del mercado asegurador. 1. Bases del problema. 2. La ley aplicable a los contratos internacionales de reaseguro. 3. La ley aplicable a los contratos internacionales de intermediación de seguros privados. 4. La ley aplicable a los contratos internacionales de seguro: dualidad de regímenes. 5. A modo de conclusiones. IV. Valoración de la coherencia del Derecho de la Unión Europea en el ámbito de la protección del consumidor de seguros. V. Mecanismos para la protección del consumidor de seguros y del mercado interior frente a los efectos de la dispersión conflictual. 


\section{Los contratos internacionales intervinientes en el mercado asegurador: cuestiones clave}

1. El sector asegurador, además de ser un sector jurídico especialmente proclive a la litigiosidad y a la internacionalización, es uno de los más complejos de la contratación, y ello tanto en el ámbito interno como en el internacional ${ }^{1}$. En palabras del profesor Fuentes Camacho, dicha complejidad, predicable tanto del plano interno como del internacional, es debida, entre otros factores, a la extrema dificultad de su regulación, así como a la "extraordinaria diversidad de figuras que abarca dicha modalidad contractual y, en su caso, de intereses y valores materialmente protegibles presentes sólo en algunas y ausentes en las restantes" 2 .

A mi modo de ver, entre los factores condicionantes, que acarrean este plus de complejidad, podemos destacar los siguientes.

2. Por un lado, el factor condicionante, de mayor repercusión en la práctica, lo constituye la amplia heterogeneidad o variedad de categorías contractuales existentes en el mercado asegurador, los cuales, como consecuencia fundamentalmente de la gran diversidad de intereses y de valores subyacentes a las mismas, reciben un tratamiento diferente, tanto en el plano conflictual como en el ámbito de la competencia judicial internacional, que son los dos problemas fundamentales de Derecho internacional privado que plantean los señalados contratos internacionales y que ha de resolver el órgano jurisdiccional u operador jurídico. De hecho, la tipología de los contratos internacionales de seguro es muy variada.

Además, los contratos de seguro coexisten, en la práctica, con los contratos de reaseguro, los cuales se celebran, en su caso, entre la entidad aseguradora y el reasegurador.

Al margen de lo señalado, en la actualidad, los contratos de intermediación de seguros privados están adquiriendo un creciente protagonismo. Cada vez es más habitual que la contratación de seguros se lleve a cabo, no de un modo directo (por medio de la propia empresa de seguros o un empleado de las mismas), sino de un modo indirecto, es decir, recurriendo a los mediadores o intermediarios de seguros privados. La relación jurídica existente con los intermediarios de seguro se materializa en un contrato de intermediación o distribución de seguros. Tienen la consideración de mediadores o intermediarios de seguros, tanto los agentes de seguros, como los corredores de seguros (broker). El agente de seguros puede ser tanto "exclusivo" (si actúa en nombre y por cuenta de una entidad aseguradora), como "vinculado" (si actúa en nombre y por cuenta de varias compañías aseguradoras). El operador de banca-seguros (que son entidades de crédito que realizan la actividad de mediación de seguros, como agentes de seguros, utilizando las redes de distribución de las mismas) puede ser "exclusivo" o "vinculado". Sin embargo, los corredores de seguros no actúan para la entidad aseguradora, sino para el cliente o consumidor de seguros, buscando para el mismo la mejor opción de seguro. Ambas modalidades de intermediarios de seguros privados pueden ser tanto una persona física como una persona jurídica. El agente de seguros, al igual que el corredor de seguros, tienen como actividad profesional distribuir los productos de seguros (o, en su caso, de reaseguros) a cambio de una remuneración.

3. Y, por otro lado, el desequilibrio en la posición negocial de las partes contractuales, existente con carácter general en el mercado asegurador, no es tan acusado en todas las modalidades contractuales existentes en el sector asegurador ni en todos los contratos de seguro.

Dicho desequilibrio es evidente en los contratos de seguro (aunque no en todas sus modalidades se aprecia la misma necesidad de protección); y mucho menos acusado en los contratos de reaseguro, ya que, a diferencia de lo que acontece con los contratos de seguro (que se celebran entre un particular [asegurado o tomador del seguro] y un profesional [compañía aseguradora]), los contratos

\footnotetext{
${ }^{1}$ Este trabajo se encuadra en el Proyecto de Investigación "La modernización del Derecho de seguros en el marco económico actual" (núm. De referencia DER2014-59182-P), de la convocatoria 2014, financiado por el Ministerio de Economía y Competitividad, dentro del Programa estatal de Fomento de la Investigación Científica y Técnica de Excelencia en el marco del Plan Estatal de I + D + I (Modalidad 1-B); gestionado por la Universidad Rovira i Virgili de Tarragona y con una duración de tres años.

${ }^{2}$ V. Fuentes Camacho, Los contratos de seguro y el Derecho Internacional Privado en la Unión Europea, Colección "Cuadernos de Estudios Europeos”, Fundación Universidad Empresa, Civitas, Madrid, 1999, p. 104.
} 
de reaseguro se celebran entre profesionales del sector asegurador, los cuales, al menos a priori, no necesitan de protección.

En relación con los contratos de intermediación de seguros, la necesidad de protección es menor en los contratos de agencia de seguros (celebrados entre profesionales [agente de seguros y entidad aseguradora]) que en los contratos de mediación o corretaje de seguros (celebrados entre un profesional [corredor de seguros] y un particular [asegurado]). Dicha necesidad de protección no sería tan acusada en la eventual relación jurídica existente entre la entidad aseguradora y el corredor de seguros, la cual, en el caso de existir, se materializaría en otro contrato mercantil.

4. Al margen de lo señalado, otro presupuesto de partida, de los problemas de Derecho internacional privado, es la acentuada concurrencia normativa existente en el sector asegurador, lo cual se aprecia especialmente en sede de ley aplicable, que es el sector que vamos a tratar en el presente estudio.

\section{Coexistencia de la Directiva sobre la distribución de seguros de 2016 con el Derecho interna- cional privado europeo}

\section{Planteamiento general}

5. El mercado asegurador es uno de los sectores en los que coexisten las Directivas elaboradas por las instituciones europeas para determinados sectores de la contratación ${ }^{3}$ con el Derecho internacional privado europeo; lo cual acarrea complejos problemas de conciliación de las disposiciones materiales de carácter imperativo de las Directivas europeas sectoriales (el llamado Derecho material europeo) con el Derecho internacional privado europeo y, más en concreto, con las normas de conflicto contenidas en uno de los dos Reglamentos estrella del Derecho internacional privado europeo: el Reglamento (CE) núm. 593/2008 del Parlamento Europeo y del Consejo, de 17 de junio de 2008, sobre la ley aplicable a las obligaciones contractuales (en lo sucesivo, Reglamento "Roma I") ${ }^{4}$

En el ámbito de la distribución internacional del seguro, en el sector del Derecho aplicable, tenemos que hacer frente a los problemas de coordinación que se producen por la coexistencia de la Directiva (UE) 2016/97 del Parlamento Europeo y del Consejo, de 20 de enero de 2016, sobre la distribución de seguros (versión refundida) ${ }^{5}$ con las normas de conflicto consagradas por el Reglamento "Roma I" para determinar la ley aplicable a los contratos internacionales. El presente estudio se va a centrar en la problemática que plantean los contratos internacionales intervinientes en el mercado asegurador desde la perspectiva del Derecho aplicable, que es el que mayor complejidad presenta debido a la coexistencia

\footnotetext{
${ }^{3}$ En concreto, en la actualidad, existen Directivas europeas sectoriales en los siguientes sectores de la contratación: el de los seguros, el de los contratos de consumo (siendo éste el sector que cuenta con un mayor número de Directivas europeas), el de los contratos individuales de trabajo y el de los contratos de agencia comercial.

${ }^{4}$ DOUE, de 4 de julio de 2008, núm. L 177/6.

5 DOUE, de 2 de febrero de 2016, núm. L 26/19. Dicha Directiva ha sustituido a la anteriormente vigente Directiva 2002/92/CE del Parlamento Europeo y del Consejo, de 9 de diciembre de 2002, sobre la mediación en los seguros (DOCE, de 15 de enero de 2003, núm. L 9/3). Esta última Directiva, que tenía por objeto el tratamiento de la problemática relativa a la mediación de seguros y de reaseguros privados, entró en vigor el 15 de enero de 2003; fecha en la cual se produjo la derogación de la anteriormente vigente Directiva 77/92/CEE del Consejo, de 13 de diciembre de 1976, relativa a las medidas destinadas a facilitar el ejercicio efectivo de la libertad de establecimiento y de la libre prestación de servicios para las actividades de agente y de corredor de seguros (ex grupo $630 \mathrm{CITI}$ ) y por la que se establecían, en particular, medidas transitorias para estas actividades (DOCE, de 31 de enero de 1977, núm. L 26/14). Tal como se deriva de la anteriormente vigente Directiva 2002/92/CE, el objetivo de la actividad de mediación de seguros es ayudar al cliente a celebrar o ejecutar un contrato de seguro o, en su caso, de reaseguro; gestionar profesionalmente los siniestros; así como efectuar actividades de peritaje y de liquidación de siniestros. En definitiva, la Directiva 2002/92/CE sobre la mediación en los seguros, la cual fue transpuesta a todos los ordenamientos jurídicos internos de los Estados miembros de la Unión Europea, fiscalizó el acceso y adecuado ejercicio de la actividad de los intermediarios de seguros privados (básicamente, de los agentes de seguros y corredores de seguros) en aras de favorecer la profesionalización de los mismos y la transparencia en el sector en torno a cuestiones de suma relevancia (como, por ejemplo, el deber de información y asesoramiento que tiene el mediador de seguros con respecto al cliente o asegurado, así como el importe de las comisiones de los intermediarios de seguros).
} 
de un marco normativo general (el Reglamento "Roma I") con un marco normativo específico (la Directiva sobre la distribución de seguros).

En el ámbito del Derecho procesal civil internacional no se produce tal problemática, ya que, en el sector por nosotros abordado, el de la distribución internacional del seguro, la Directiva sobre la distribución de seguros de 2016 no ha consagrado ninguna norma específica de competencia judicial internacional. De hecho, dicha Directiva no contiene ninguna norma de competencia judicial internacional ni de competencia territorial interna ${ }^{6}$.

\section{Transposición al ordenamiento jurídico español de la Directiva sobre la distribución de seguros de 2016 por la vía del reciente Real Decreto-Ley 3/2020}

6. Como es sabido, las Directivas europeas carecen de efecto directo, por lo que, para resultar operativas, han de ser objeto de transposición, a los respectivos ordenamientos jurídicos internos de los Estados miembros de la UE, en el plazo para ello fijado. El plazo establecido a nivel europeo, para la transposición de la Directiva sobre la distribución de seguros de 2016, al Derecho interno de todos los Estados miembros de la UE, ya ha transcurrido.

7. Por lo que respecta a la transposición de la Directiva (UE) 2016/97 sobre la distribución de seguros, al ordenamiento jurídico español, además de tardía, es criticable como consecuencia de haberse llevado a cabo por medio de una técnica jurídica inadecuada, la cual está pensada para casos de urgente necesidad. Lamentablemente, los partidos políticos están tendiendo a utilizar el Real Decreto-Ley cuando no encuentran el apoyo político necesario para la elaboración de leyes, lo cual está desvirtuando una técnica legislativa que no ha sido concebida para lo que está siendo utilizada en el panorama político español por partidos de distinto signo.

Por lo que al sector de la distribución internacional del seguro se refiere, en un primer momento, la transposición de la susodicha Directiva al ordenamiento jurídico español, se pretendía llevar a cabo, como suele ser habitual en la práctica, por medio de una norma con rango de ley y, más en concreto, por una Ley de distribución de seguros y reaseguros privados. De hecho, con tal intencionalidad, se elaboró un Proyecto de Ley de distribución de seguros y reaseguros privados, el cual fue publicado, el 21 de mayo de 2019, en el Diario Oficial de las Cortes. No obstante, debido a problemas de índole política, la ansiada y esperada Ley española de distribución de seguros y reaseguros privados no consiguió ver finalmente la luz. El contenido del Proyecto de Ley de distribución de seguros y reaseguros privados se ha trasladado a un Real Decreto-Ley: el Real Decreto-Ley 3/2020, de 4 de febrero, de medidas urgentes por el que se incorporan al ordenamiento jurídico español diversas directivas de la Unión Europea en el ámbito de la contratación pública en determinados sectores; de seguros privados; de planes y fondos de pensiones; del ámbito tributario y de litigios fiscales?.

Pero además de resultar inapropiada la técnica normativa utilizada por el legislador español para la transposición de una Directiva europea y de haberlo hecho fuera del plazo para ello establecido, es criticable igualmente que un tema tan crucial haya sido utilizado para la transposición, al ordenamiento jurídico español, de Directivas europeas que abordan diversos temas. De este modo, el sector de la distribución de seguros privados ha sido abordado en el mismo texto normativo que otros temas de índole muy diversa: la contratación pública en determinados sectores, los planes y fondos de pensiones, así como el ámbito tributario y los litigios fiscales. Es evidente que el mentado Real Decreto-Ley 3/2020, aunque únicamente está encaminado a llevar a cabo la transposición de diversas Directivas europeas, se caracteriza por ser extremadamente heterogéneo en lo referente a los temas tratados por el mismo, que como puede apreciarse son de índole muy diversa. A mi modo de ver, el sector de la distribución

\footnotetext{
${ }^{6}$ Para un estudio exhaustivo análisis de los foros, en materia de seguros, vid., muy especialmente, A.L. CALvo CARAvaCa/J. Carrascosa González/C. Caamiña Domínguez, Litigación internacional en la Unión Europea I, Thomson Reuters, Aranzadi, Navarra, 2017, $1^{\text {a }}$ ed., pp. 444-461.

${ }^{7}$ BOE, de 5 de febrero de 2020, núm. 31.
} 
internacional del seguro es de tal relevancia como para ser tratado de un modo independiente y en una norma con rango de Ley. En un futuro próximo, se espera contar con una Ley española de distribución de seguros y reaseguros privados, que sustituya al Real Decreto-Ley 3/2020, que es lo que se pretendió inicialmente y que en el último momento se vio frustrado.

El mentado Real Decreto-Ley 3/2020 lleva a cabo la transposición de la Directiva (UE) 2016/97 del Parlamento Europeo y del Consejo, de 20 de enero de 2016, sobre la distribución de seguros, en el Título I de su Libro segundo ("Medidas para la adaptación del derecho español a la normativa de la Unión Europea en materia de seguros privados y planes y fondos de pensiones"). Dicho título se divide en Capítulos, Secciones y Subsecciones. En concreto, la regulación del sector abordado aparece contenida en los arts. 127-211.

8. Los problemas de coordinación que se producen, en sede de ley aplicable, entre el Reglamento "Roma I" y el Real Decreto-Ley 3/2020, habrán de solventarse con arreglo al principio de conciliación en el seno del ordenamiento jurídico de la Unión Europea ${ }^{8}$. De conformidad con el referido principio, los instrumentos normativos del ordenamiento jurídico de la Unión Europea no pueden concebirse como compartimentos estancos, sino que han de considerarse como un todo unitario; han de responder a los mismos valores e intereses, que son los del ordenamiento jurídico al cual pertenecen (el ordenamiento jurídico europeo). En aras de conseguir dicho objetivo, el Reglamento "Roma I" dispone de determinados instrumentos o mecanismos para alcanzar la ansiada coherencia valorativa o conciliación, en el seno de la Unión Europea, y la consiguiente aplicación, en los litigios planteados por los contratos internacionales intervinientes en el mercado asegurador, del Derecho material europeo sobre distribución de seguros (la Directiva 2016/97 sobre la distribución de seguros) tal como haya sido transpuesta por el ordenamiento jurídico del foro (en el supuesto de plantearse el litigio internacional ante un Tribunal español, por el Real Decreto-Ley 3/2020).

Al menos a priori, el Reglamento "Roma I" consagra, en su articulado, dos cauces que pueden servir, en el supuesto de concurrir determinados presupuestos, para alcanzar la ansiada coherencia de valores entre las Directivas elaboradas por las instituciones europeas para determinados sectores de la contratación (las comúnmente denominadas Directivas europeas sectoriales [que están en auge y permiten atender a la especificidad de ciertos ámbitos de la contratación]) y las normas de conflicto consagradas por el Reglamento "Roma I" para determinar la ley aplicable a los contratos internacionales, es decir, a los contratos cuyos elementos están vinculados a más de un Estado: la cláusula general de protección del Derecho de la Unión Europea (art. 3.4) y las "leyes de policía" (art. 9). Para la intervención de estos dos mecanismos han de concurrir ciertos presupuestos. En otro apartado del presente trabajo habremos de analizar si tales presupuestos concurren o no en el sector por nosotros abordado: el de la distribución internacional del seguro.

9. Al margen de lo señalado, en el sector de la distribución internacional de seguros, cuando nos encontremos ante un contrato de agencia de seguros, a través del cual se materializa la relación jurídica existente entre el agente de seguros (exclusivo, vinculado u operador de banca-seguros) y la entidad aseguradora, se aplica, subsidiariamente, la Directiva 86/653/CE del Consejo, de 18 de diciembre de 1986, relativa a la coordinación de los derechos de los Estados miembros en lo referente a los agentes comerciales independientes 9 . Dicha Directiva europea sectorial, que es considerada como una Directiva "de mínimos" y que establece un nivel mínimo de protección al agente comercial frente al principal, ha sido transpuesta, a los ordenamientos jurídicos internos de todos los Estados miembros de la Unión Eu-

\footnotetext{
${ }^{8}$ El principio de conciliación del Derecho internacional privado europeo, con el Derecho europeo material, fue preconizado por dos prestigiosos profesores alemanes: JAYME/KoHLER, "Das Internationale Privat- und Verfahrungsrecht der EG 1993 - Spannungen zwischen Staatsverträgen und Richtlinien”, IPRax, 1993, núm. 6, pp. 357-371; id., "L'interaction des règles de conflit contenues dans le droit dérivé de la Communauté européenne et des conventions de Bruxelles et de Rome", RCDIP, 1995, vol. 84, núm. 1, pp. 1-40.

${ }_{9}$ DOCE, de 31 de diciembre de 1986, núm. L 382. En relación con la necesidad de conciliar, en los contratos internacionales de agencia comercial, la Directiva de agencia de 1986 con el Reglamento "Roma I", vid. H., Aguilar GriedER, "El impacto del Reglamento 'Roma I' en el contrato internacional de agencia”, $C D T$, 2011, vol. 3, núm. 1, pp. 24-46.
} 
ropea. La transposición de la Directiva de agencia comercial de 1986, al ordenamiento jurídico español, se ha llevado a cabo por la Ley 12/1992, de 27 de mayo, sobre el contrato de agencia (en lo sucesivo, LCA 12/1992) ${ }^{10}$. Al igual que acontece con la Directiva europea sobre la distribución de seguros, la coordinación de las disposiciones materiales de carácter imperativo de la Directiva de agencia comercial (y, más en concreto, si conoce un Tribunal español, de la LCA 12/1992) con las normas del Reglamento "Roma I" aplicables a los contratos internacionales de agencia comercial, se llevará a cabo con arreglo al principio de conciliación del ordenamiento jurídico de la Unión Europea.

\section{Dispersión conflictual en el seno del mercado asegurador}

\section{Bases del problema}

10. El legislador europeo ha introducido una importante novedad, en el Reglamento "Roma I", que afecta al sector asegurador. Dicha novedad consiste en haber reducido, más que notablemente, la dispersión normativa existente al amparo del Convenio sobre la ley aplicable a las obligaciones contractuales, hecho en Roma el 19 de junio de 1980 (en adelante, Convenio de Roma) ${ }^{11}$. El régimen jurídico establecido por el antecesor directo del Reglamento "Roma I" (es decir, por el Convenio de Roma de 1980) era, además de extremadamente complejo, extraordinariamente disperso; lo cual dificultaba, en gran medida, su aplicación por el operador jurídico. En concreto, en el marco del Convenio de Roma, los contratos de seguro podían quedar sometidos, en función básicamente de dos elementos (la localización del riesgo y el establecimiento del asegurador), a las normas conflictuales del Convenio de Roma, a las de las Directivas comunitarias (europeas) sobre seguros o a las de los sistemas autónomos de los Estados miembros. De hecho, los contratos de seguro, que cubrían riesgos situados en el territorio comunitario, quedaban excluidos del ámbito de aplicación material del Convenio de Roma ${ }^{12}$.

Sin embargo, el Reglamento "Roma I" incluye, dentro de su ámbito de aplicación material, con una excepción aislada, a todos los contratos internacionales de seguro, así como al resto de los contratos internacionales intervinientes en el mercado asegurador: contratos internacionales de reaseguro y contratos internacionales de intermediación de seguros privados (lo cual incluye tanto a los contratos de agencia de seguros como a los contratos de mediación o corretaje). Por lo que se refiere al sector asegurador, la única salvedad o exclusión del ámbito de aplicación material del Reglamento "Roma I", que es extraordinariamente específica y de escasa repercusión práctica, aparece contemplada expresamente en el apartado 2 j) del art. 1 del Reglamento. La señalada excepción se refiere a los contratos de seguro derivados de operaciones realizadas por organizaciones que no sean las empresas y que tengan como objetivo la concesión de prestaciones a favor de determinados trabajadores ${ }^{13}$. Tal como se desprende del apartado transcrito, el legislador europeo únicamente ha excluido, del ámbito de aplicación material del Reglamento "Roma I", un tipo muy concreto y específico de contrato de seguro.

En suma, tal como podemos derivar de lo señalado, en el marco del Reglamento "Roma I", a diferencia de lo que acontecía con su antecesor directo (el Convenio de Roma), no existe dispersión normativa en cuanto a los instrumentos normativos aplicables, ya que todos los contratos de seguro, con

\footnotetext{
10 BOE, de 29 de mayo de 1992, núm. 129.

11 DOCE, de 9 de octubre de 1980, núm. L 266.

${ }^{12}$ En relación al alto grado de dispersión normativa existente al amparo del Convenio de Roma de 1980, en relación con los contratos de seguro, vid., muy especialmente, F.J., GARCIMARTín AlfÉREz, "El Reglamento 'Roma I' sobre ley aplicable a las obligaciones contractuales: ¿cuánto ha cambiado el Convenio de Roma de 1980?”, Diario La Ley (Unión Europea), de 30 de mayo de 2008, núm. 6957, pp. 1-10, p. 8.

13 En concreto, de conformidad con el apartado 2 j) del art. 1 del Reglamento "Roma I", quedan excluidos de su ámbito de aplicación material, "los contratos de seguros que se derivan de operaciones realizadas por organizaciones que no sean las empresas a las que se hace referencia en el art. 2 de la Directiva 2002/83/CE del Parlamento Europeo y del Consejo, de 5 de noviembre de 2002, sobre el seguro de vida, y que tengan como objetivo la concesión de prestaciones a favor de trabajadores por cuenta ajena o por cuenta propia que sean parte de una empresa o grupo de empresas, actividad profesional o conjunto de actividades profesionales, en caso de fallecimiento, supervivencia, cesación o reducción de actividades, enfermedad relacionada con el trabajo o accidentes laborales".
} 
la salvedad de la exclusión específica que acabamos de poner de manifiesto, quedan incluidos dentro del ámbito de aplicación material del Reglamento "Roma I"; el cual se aplica, pues, a todos los contratos internacionales intervinientes en el sector asegurador.

11. En el ámbito del Reglamento "Roma I", como va a quedar patente en el presente estudio, la dispersión conflictual tiene lugar, en el ámbito del mercado asegurador, exclusivamente en el seno del propio instrumento normativo aplicable, es decir, del Reglamento "Roma I"; en el sentido en que no todos los contratos internacionales existentes en el sector asegurador están sometidos, ni al mismo régimen de Derecho aplicable del Reglamento, ni a la misma norma de conflicto.

12. Por un lado, la referida dispersión conflictual tiene su origen en la aplicación de distintos regímenes de Derecho aplicable, de los dos que aparecen consagrados por el Reglamento "Roma I" (el general y el especial), a los contratos internacionales intervinientes en el mercado asegurador. De hecho, como vamos a poder comprobar en las líneas siguientes, a algunos de dichos contratos internacionales se les aplica el régimen general de Derecho aplicable (contenido, básicamente, en los arts. 3 y 4 del Reglamento "Roma I"); mientras que a otros contratos internacionales se les somete al régimen especial de Derecho aplicable consagrado por el legislador europeo en el art. 7 del Reglamento ${ }^{14}$.

Al menos desde un punto de vista teórico, el régimen general de determinación de la ley aplicable del Reglamento "Roma I" parte implícitamente de un presupuesto: el equilibrio en la posición negocial de las partes de la relación contractual. No obstante, la práctica nos muestra que el susodicho presupuesto no se cumple en relación con todas las categorías contractuales sometidas al régimen general de Derecho aplicable. Tal es el caso, por ejemplo, de los contratos de agencia comercial y de los contratos de distribución, en los cuales, pese a quedar sometidos al régimen general de Derecho aplicable, el agente comercial (en los contratos de agencia comercial) y el distribuidor (en los contratos de distribución) suele ser, en la inmensa mayoría de las ocasiones, la parte débil de la relación litigiosa.

Sin embargo, el régimen especial de Derecho aplicable (previsto, como es sabido, en los arts. 5-8 del Reglamento "Roma I"), dentro del cual quedan incluidos determinados contratos internacionales de seguro (aunque, como vamos a exponer a lo largo del presente trabajo, no todos los contratos de seguro quedan sujetos al régimen especial), parte del presupuesto opuesto: el desequilibrio en la posición negocial de las partes del contrato. Tal como se desprende del Considerando 23 del Reglamento "Roma I", el objetivo prioritario del señalado régimen especial, de determinación de la ley aplicable, es proteger a la parte débil de la relación litigiosa por medio de normas de conflicto más favorables a sus intereses que las que conforman el régimen general. A dicha finalidad tuitiva responde, al menos a priori, el régimen especial de Derecho aplicable previsto por el legislador europeo en el art. 7 del Reglamento "Roma I". Como es sabido, en el marco del Convenio de Roma de 1980, únicamente quedaban sujetos al régimen especial de Derecho aplicable los contratos de consumo y los contratos individuales de trabajo; pero no los contratos de seguro ni los contratos de transporte. El Reglamento "Roma I" ha extendido el régimen especial de Derecho aplicable a estos dos últimos tipos contractuales; lo cual ha constituido una novedad de indudable trascendencia con respecto a su antecesor directo (el Convenio de Roma).

13. Y, por otro lado, la dispersión conflictual, en el seno del mercado asegurador, también trae causa en la diversidad de normas de conflicto aplicables a los contratos internacionales que intervienen en el mercado asegurador, en el cual los contratos de seguro coexisten con los contratos de reaseguro, así como con los contratos de intermediación de seguros, dentro de los cuales tienen cabida tanto los contratos de agencia de seguros (celebrados entre el agente de seguros y la compañía aseguradora) como los contratos de corretaje o de mediación de seguros (celebrados entre el cliente y el corredor de seguros). De este modo, a la complejidad, derivada de la diversidad de regímenes de Derecho aplicable, hay que sumarle la aplicación, en función del tipo de contrato de seguro de que se trate, de diferentes normas de conflicto dentro de un mismo régimen de Derecho aplicable, en concreto, del régimen especial de ley aplicable consagrado, en el art. 7 del Reglamento "Roma I", por el legislador europeo. Por lo tanto, al

${ }^{14}$ Vid. el siguiente apartado del presente trabajo. 
operador jurídico se le origina un plus de complejidad debido a la variedad y extrema complejidad de las normas de conflicto aplicables en función del tipo de contrato de seguro de que se trate.

14. En suma, la extrema complejidad para la resolución, por el órgano jurisdiccional u operador jurídico, de la problemática relativa a la ley aplicable, en el ámbito del sector asegurador, es debida, muy especialmente, a los dos factores que acabamos de poner de manifiesto.

De lo señalado se desprende claramente que, a diferencia de lo que acontecía en el seno del Convenio de Roma de 1980 sobre la ley aplicable a las obligaciones contractuales, en el marco del Reglamento "Roma I", la dispersión normativa no es predicable en cuanto a los instrumentos normativos aplicables, ya que los contratos internacionales existentes en el sector asegurador, salvo el supuesto específico anteriormente comentado, quedan insertos dentro del ámbito de aplicación material del Reglamento "Roma I" y, por consiguiente, se resuelven con arreglo al sistema conflictual por el mismo consagrado.

No obstante, como ha quedado patente en las líneas anteriores, la dispersión normativa sí que es predicable en cuanto al régimen de ley aplicable (general o especial) y en lo referente a la norma de conflicto aplicable, por el juez u operador jurídico, en el seno del propio instrumento normativo internacional (europeo), es decir, del Reglamento "Roma I".

15. Como se puede apreciar de lo anteriormente señalado y vamos a desarrollar a lo largo del presente estudio, los contratos internacionales que intervienen en el sector asegurador no están sujetos a un tratamiento conflictual uniforme. De facto, en el mercado asegurador, se vislumbra una evidente dispersión en el tratamiento y solución de los problemas de ley aplicable; lo cual no acontece en otros sectores de la contratación internacional ${ }^{15}$. Ello dota de una enorme complejidad al sector asegurador. De hecho, a este sector se le ha considerado el más complejo de la contratación internacional. El legislador europeo, a la hora de establecer dicho tratamiento o solución conflictual, en el marco del Reglamento "Roma I", ha tenido en cuenta diversos criterios, que son básicamente los tres siguientes.

En primer lugar, el criterio más relevante, que ha tenido en cuenta el legislador europeo en sede de ley aplicable, es el de la modalidad de contrato internacional interviniente en el mercado asegurador y del tipo de contrato de seguro de que se trate. Como es sabido, la tipología de contratos de seguro es extraordinariamente variada. Siendo consciente de la relevancia de dicho factor, el legislador europeo ha consagrado, en el Reglamento "Roma I", una solución conflictual diferente para los contratos de seguro que para los contratos de reaseguro y los contratos de intermediación de seguros; estableciendo, además, un tratamiento y solución conflictual diferente según la modalidad de contrato de seguro de que se trate.

En segundo término, otro criterio que ha tenido en cuenta el legislador europeo a efectos conflictuales, en relación con el sector asegurador, es el del nivel de protección requerido, del asegurado o tomador del seguro, en cada categoría o modalidad contractual; lo cual varía en gran medida, en el seno del mercado asegurador, de un tipo contractual a otro. Es obvio que la necesidad de protección no va a ser la misma en un contrato de seguro que en un contrato de reaseguro o que en un contrato de intermediación de seguros. Y, además, dentro de estos últimos, el nivel de protección exigido no va a ser el mismo para un contrato de agencia de seguros, celebrado entre dos profesionales, que para un contrato de corretaje o de mediación de seguros, a través del cual se materializa la relación jurídica existente entre el corredor de seguros y el cliente ${ }^{16}$. El factor al cual estamos haciendo referencia está estrechamente interrelacionado con el anterior, ya que, como he señalado, la necesidad de protección varía notablemente, dentro del mercado asegurador, en función de la modalidad contractual de que se trate.

$\mathrm{Y}$, en tercer lugar, otro criterio que ha considerado el legislador europeo en sede de ley aplicable, en el seno del mercado asegurador, es el del riesgo cubierto por el contrato de seguro de que se trate. En

\footnotetext{
${ }^{15}$ A excepción del sector de los contratos internacionales de consumo, en el cual, como es sabido, algunos contratos de consumo, como consecuencia de cumplirse determinados presupuestos materiales y espaciales, quedan incluidos dentro del régimen especial de Derecho aplicable del Reglamento "Roma I" (en concreto, del art. 6); mientras que otros quedan sujetos al régimen general de ley aplicable del Reglamento. No obstante, en el sector del consumo, la dispersión conflictual es menor que en el seno del mercado asegurador.

${ }^{16}$ Este factor se analizará con más detalle en los siguientes apartados del presente trabajo.
} 
relación con el riesgo cubierto, el legislador europeo ha tenido en cuenta dos factores. Por un lado, el tipo de riesgo cubierto por el contrato de seguro. Y, por otro lado, el legislador europeo ha tenido muy en cuenta, a efectos del tratamiento conflictual, el criterio del lugar de localización del riesgo cubierto, en función de si el mismo se encuentra localizado en el área o territorio de la Unión Europea (esto es, en un Estado miembro) o en un Estado tercero (es decir, en un Estado no miembro de la Unión Europea). Dicho criterio espacial únicamente se tiene en cuenta en relación con los contratos internacionales de seguro, pero no afecta a las restantes categorías contractuales existentes en el mercado asegurador. E incluso, como ya se verá, no se tiene en cuenta en todas las modalidades de contratos de seguro. Como posteriormente concretaré, este último criterio, el espacial, que considero extremadamente delicado y que a mi modo de ver carece actualmente de justificación, se fundamenta exclusivamente en cargas anteriores del legislador europeo y, más en concreto, en las existentes al amparo del Convenio de Roma de 1980 sobre la ley aplicable a las obligaciones contractuales. Por ello, a mi modo de ver, que el legislador europeo haya tenido en cuenta este factor, en el marco del Reglamento "Roma I", es erróneo y anacrónico por carecer, en la actualidad, de justificación práctica teniendo en cuenta la inclusión, en el articulado del propio Reglamento (en concreto, en su art. 7), de las normas de conflicto de las Directivas europeas de seguros.

A continuación vamos a pasar a exponer la amplia variedad de soluciones conflictuales elaboradas, con base en los criterios y presupuestos de partida que acabamos de poner de manifiesto, por el legislador europeo, en el marco del Reglamento "Roma I", para los contratos internacionales intervinientes en el mercado asegurador.

\section{La ley aplicable a los contratos internacionales de reaseguro}

16. En el sector del mercado asegurador, los contratos de reaseguro gozan de una indudable trascendencia. Dichos contratos se celebran entre dos profesionales del sector asegurador, en concreto, entre la entidad aseguradora y el reasegurador ${ }^{17}$. En relación con la problemática que plantea esta categoría contractual, en el terreno del Derecho aplicable, es preciso tener en cuenta varias premisas.

Por un lado, en el marco del Reglamento "Roma I", al igual que ocurría con su antecesor directo (el Convenio de Roma de 1980), los contratos internacionales de reaseguro quedan incluidos dentro del ámbito de aplicación material del Reglamento. Ello se desprende, claramente, del anteriormente mentado apartado 2 j) del art. 1 del Reglamento "Roma I", el cual tan sólo excluye, de su ámbito material, un tipo muy concreto y específico de contrato de seguro, al cual anteriormente hicimos referencia.

Por otro lado, tal como señala el apartado $1^{\circ}$ del art. 7 del Reglamento "Roma I", los contratos internacionales de reaseguro quedan excluidos del ámbito material del art. 7 del Reglamento. Por lo tanto, los mismos quedan excluidos del régimen especial de Derecho aplicable consagrado por el Reglamento, tal como ocurría en el marco del Convenio de Roma.

Desde una perspectiva de lege lata, con base en los dos preceptos señalados se desprende, claramente, que los contratos internacionales de reaseguro quedan sujetos al régimen general de ley aplicable del Reglamento "Roma I", es decir, a sus arts. 3 y 4, los cuales, como es sabido, constituyen el núcleo básico o central del susodicho Reglamento europeo, el aplicable a la generalidad de los contratos internacionales, esto es, a todas las categorías contractuales que no quedan sometidas al régimen especial de Derecho aplicable consagrado por el legislador europeo, para cuatro tipos contractuales (contratos de transporte de mercancías y de pasajeros, contratos de consumo, contratos de seguro y contratos individuales de trabajo), en los arts. 5-8 del Reglamento ${ }^{18}$.

\footnotetext{
${ }^{17}$ En relación con el sector del reaseguro, vid., muy especialmente, J.L. GARCíA-PITA y LASTRES, El reaseguro marítimo, entre el Derecho español y el "common law”: una visión armonizadora, Aranzadi, Pamplona, 2011.

${ }^{18}$ En relación con el modus operandi de los mencionados preceptos del Reglamento "Roma I", vid., entre otros muchos, H., Aguilar Grieder, “Alcance de los controvertidos artículos 3 y 4 del Reglamento (CE) núm. 593/2008: perspectiva de lege lata y propuestas de lege ferenda", CDT, 2014, vol. 6, núm. 1, pp. 45-67, así como las referencias en dicho trabajo citadas.
} 
17. Desde una perspectiva de lege ferenda, me parece apropiado que los contratos internacionales de reaseguro queden sometidos al régimen general de Derecho aplicable consagrado por el Reglamento "Roma I", ya que, en esta categoría contractual, no existe un desequilibrio, al menos acusado, en la posición negociadora de las partes del contrato. De hecho, el contrato se celebra entre profesionales del sector asegurador (entidad aseguradora y compañía reaseguradora) que, al menos a priori, no necesitan de protección. Y, como anteriormente recalcamos, el régimen general de determinación de la ley aplicable del Reglamento "Roma I" parte implícitamente, al menos desde un punto de vista teórico o conceptual, de un presupuesto: el equilibrio en la posición negocial de las partes de la relación contractual. Sin embargo, detrás del régimen especial de Derecho aplicable del Reglamento, subyace, fundamentalmente, una finalidad tuitiva, esto es, de protección de la parte débil de la relación litigiosa. Ambos regímenes de Derecho aplicable parten, al menos a priori, de presupuestos contrapuestos.

18. Por otro lado, desde una perspectiva de lege lata, en defecto de elección de ley por las partes del contrato internacional de reaseguro (en los términos permitidos por el art. 3 del Reglamento "Roma I"), el mismo quedará sujeto a la ley del país en el cual el reasegurador tenga su residencia habitual ${ }^{19}$. A dicho resultado se llega, tanto por la vía del apartado $2^{\circ}$ del art. 4 del Reglamento "Roma I" (ya que el reasegurador es la parte que lleva a cabo la "prestación característica del contrato" de reaseguro), como por el cauce de la norma de conflicto especial prevista, por el legislador europeo en el apartado $1 \mathrm{~b}$ ) del referido precepto, para los "contratos de prestación de servicios" (ya que, en la referida categoría contractual, el reasegurador es el "prestador del servicio").

\section{La ley aplicable a los contratos internacionales de intermediación de seguros privados}

19. En el seno del mercado asegurador, tanto en la práctica nacional como en la internacional, cada vez van adquiriendo un progresivo protagonismo los denominados contratos de intermediación o distribución de seguros privados. En la actualidad, dicha categoría contractual goza de una notable relevancia en el sector asegurador. Por ello, sorprende que el Reglamento "Roma I", pese a la especificidad que le caracteriza ${ }^{20}$, guarde silencio en relación con esta modalidad contractual. En cualquier caso, por exclusión, como no nos encontramos ante ninguna de los tipos contractuales sujetos al régimen especial de Derecho aplicable del Reglamento ni ante ninguna de las exclusiones de su ámbito de aplicación material, desde una perspectiva de lege lata, tanto los contratos de agencia de seguros (celebrados entre la entidad aseguradora y el agente de seguros), como los contratos de corretaje o de mediación de seguros (a través de los cuales se materializa la relación jurídica existente entre el cliente o consumidor de seguros y el corredor de seguros), quedan sujetos al régimen general de Derecho aplicable del Reglamento "Roma I", esto es, a sus arts. 3 y 4. De este modo, el legislador europeo, en el ámbito del Reglamento "Roma I", ha otorgado idéntico tratamiento y solución conflictual a los contratos internacionales de reaseguro que a los contratos internacionales de agencia de seguros y que a los contratos internacionales de mediación de seguros o de corretaje.

20. A mi modo de ver, desde una perspectiva de lege ferenda, ello es merecedor de una severa crítica, ya que el contrato de agencia de seguros y el contrato de mediación de seguros o de corretaje no requieren del mismo nivel de protección. Ello es debido a que, como anteriormente se adelantó, así como el contrato de agencia de seguros se celebra entre profesionales (en concreto, entre el agente de seguros y la entidad aseguradora), con el contrato de mediación de seguros o de corretaje no acontece lo

\footnotetext{
${ }^{19}$ En relación con la problemática de la ley aplicable al contrato internacional de reaseguro, vid., muy especialmente, J.J., VARRA PARRA, "La ley aplicable al contrato de reaseguro internacional", Revista Española de Seguros, El nuevo régimen comunitario de los contratos internacionales de seguro, 2009, núm. 140, pp. 635-649.

${ }^{20}$ De hecho, entre los principios, subyacentes a la regulación del Reglamento "Roma I", podemos destacar la seguridad jurídica, la especificidad, la materialización (en la medida en que trata de adaptarse a la nueva realidad), la simplificación y su anhelo por la conciliación del ordenamiento jurídico de la Unión Europea.
} 
mismo, es decir, no se celebra entre profesionales del sector asegurador, sino que lo suscribe el corredor de seguros con el cliente (asegurado). De hecho, por virtud del contrato de mediación de seguros o de corretaje, el corredor de seguros ha de buscar, para el cliente (asegurado), la mejor opción de seguro, esto es, aquella que en mayor medida cubra sus necesidades.

Desde esta misma perspectiva de lege ferenda, tampoco es adecuado que el contrato de agencia de seguros quede sujeto al régimen general de determinación de la ley aplicable consagrado por el Reglamento "Roma I" en sus arts. 3 y 4, ya que, aunque el referido contrato se celebre entre profesionales del sector asegurador, en la generalidad de los supuestos (tanto nacionales como internacionales), el agente de seguros ostenta una posición negociadora más débil que la entidad aseguradora; al igual que, en los contratos internacionales de agencia comercial, el agente comercial suele ocupar la posición de parte débil de la relación litigiosa.

21. En concreto, retomando la perspectiva de lege lata, a falta de elección de ley por las partes contractuales en los términos fijados por el art. 3 del Reglamento "Roma I", ante la inexistencia de una norma de conflicto específica, en el art. 4.1 del Reglamento, para los contratos internacionales de intermediación de seguros privados, el contrato internacional de agencia de seguros, al igual que el contrato internacional de corretaje o de mediación de seguros, son susceptibles de quedar incluidos en el ámbito de la norma de conflicto especial relativa a los "contratos de prestación de servicios", consagrada por el apartado 1b) del art. 4 del Reglamento "Roma I", que es un concepto autónomo dotado de una gran amplitud que ha de interpretarse, con arreglo al principio de conciliación del ordenamiento jurídico de la Unión Europea y al principio de seguridad jurídica, del mismo modo que en el ámbito del apartado 1b) del art. 7 del Reglamento (UE) núm. 1215/2012 del Parlamento Europeo y del Consejo, de 12 de diciembre de 2012, relativo a la competencia judicial, el reconocimiento y la ejecución de resoluciones judiciales en materia civil y mercantil, denominado comúnmente como Reglamento "Bruselas I bis"21. Ello implica que se aplique la ley del país de la residencia habitual, en el momento de la celebración del correspondiente contrato, del "prestador del servicio", esto es, del agente de seguros (en el contrato de agencia de seguros) o del corredor de seguros (en el contrato de mediación de seguros o de corretaje).

A la misma conclusión se llegaría en el supuesto de aplicar el juez u operador jurídico, a ambas categorías contractuales, la norma conflictual especial relativa a los "contratos de distribución", consagrada por el apartado 1f) del art. 4 del Reglamento "Roma I". Dicha norma de conflicto especial, como consecuencia de su origen (potenciar la seguridad jurídica), responde a un concepto autónomo estricto (prueba de ello es que existe una norma de conflicto específica para los contratos de franquicia, por lo que el legislador europeo no los considera incluidos dentro de la categoría jurídica de los contratos de distribución); dentro del cual difícilmente tienen cabida, a mi modo de ver, los contratos de intermediación de seguros privados. Además, entre ambos tipos contractuales existen diferencias sustanciales. No obstante, la aplicación a los referidos contratos internacionales de la norma de conflicto relativa a los "contratos de distribución", la cual remite a la ley del país en el cual el distribuidor tenga su residencia habitual, implicaría que los mismos se regulasen por la misma ley estatal que si se aplicase la norma de conflicto, prevista por el legislador europeo, para los "contratos de prestación de servicios".

A idéntico resultado se llegaría de aplicar a los referidos contratos la primera regla subsidiaria, esto es, la contenida en el apartado 2 del art. 4 del Reglamento "Roma I" (en concreto, la ley del país donde tenga su residencia habitual el deudor de la "prestación característica del contrato" de agencia y de mediación de seguros), cuya intervención, como consecuencia de lo señalado en las líneas anteriores, no es necesaria.

22. En mi opinión, desde una perspectiva de lege ferenda, resultaría más acertado aplicar a los contratos internacionales de intermediación de seguros privados la ley del mercado afectado, esto es, la ley del país en el cual el agente de seguros o, en su caso, el corredor de seguros realice su actividad profesional.

${ }^{21}$ DOUE, de 20 de diciembre de 2012, núm. L 351/1. El referido apartado, que como es sabido está situado, en el marco del Reglamento "Bruselas I bis", en el cuarto nivel jerárquico, junto con el foro del domicilio del demandado, consagra el foro especial en materia contractual (para la generalidad de los contratos internacionales, esto es, para las categorías contractuales que no quedan sujetas al régimen especial de competencia judicial internacional). 
23. Al margen de lo señalado, otras relaciones jurídicas, que se derivan de la contratación de seguros privados a través de intermediarios, también quedan sometidas al régimen general de ley aplicable consagrado por los arts. 3 y 4 del Reglamento "Roma I".

Tal es el caso de la eventual relación jurídica existente, en su caso, entre la entidad aseguradora y el corredor de seguros, la cual se materializaría en un contrato mercantil que quedaría sometido al régimen general de Derecho aplicable consagrado por el legislador europeo en los arts. 3 y 4 del Reglamento "Roma I". La compañía aseguradora y el corredor de seguros pueden celebrar entre ellos contratos mercantiles, aunque no sin limitaciones, ya que ello únicamente es factible una vez que haya sido concluido el correspondiente contrato de seguro. No olvidemos que el corredor de seguros ha de buscar para el cliente la mejor opción de seguro, esto es, la que en mayor medida cubra sus necesidades. Por virtud de los referidos contratos mercantiles, que en ocasiones se celebran entre la entidad aseguradora y el corredor de seguros, las partes pueden pactar la gestión de la póliza, el cobro de las primas, la gestión de los siniestros, etc. En cualquier caso, como consecuencia de la obligación asumida por el corredor de seguros con respecto al cliente, las gestiones que, en su caso, se pacten entre la entidad aseguradora y el corredor de seguros no pueden colocar a este último en un conflicto de intereses. El eventual contrato mercantil, celebrado entre la entidad aseguradora y el corredor de seguros, es un contrato de gestión de negocios ajenos, por lo que es susceptible de quedar encuadrado dentro de la categoría jurídica amplia de "contrato de prestación de servicios", por lo que resultaría aplicable, en defecto de elección de ley de conformidad con el art. 3 del Reglamento "Roma I", la norma de conflicto especial relativa a la referida categoría contractual (que recordemos que es un concepto autónomo amplio ${ }^{22}$ ), la cual aparece contenida en el apartado 1b) del art. 4 del Reglamento "Roma I".

Del mismo modo, el mediador de seguros puede celebrar contratos mercantiles con sus auxiliares externos. Los auxiliares externos no tienen la condición de mediadores de seguros, pero colaboran con él en la distribución de productos de seguros, actuando por cuenta del mediador. En el supuesto de celebrarse dichos contratos, los mismos quedarán sujetos al régimen general de Derecho aplicable del Reglamento "Roma I", esto es, a los arts. 3 y 4 del susodicho cuerpo legal. Por lo tanto, en defecto de elección de ley en los términos previstos en el art. 3 del Reglamento, a dichos contratos se les aplicará, igualmente, la norma de conflicto especial relativa a los "contratos de prestación de servicios", la cual aparece contenida, como es sabido, en el apartado 1b) del art. 4 del Reglamento "Roma I".

24. En definitiva, los contratos de intermediación de seguros quedan sometidos al régimen general de Derecho aplicable del Reglamento "Roma I" que el legislador europeo ha consagrado en los arts. 3 y 4 del referido instrumento normativo. Tal como hemos puesto de manifiesto en las líneas anteriores de este trabajo, el tratamiento conflictual es idéntico para las distintas relaciones jurídicas involucradas en la mediación de seguros, esto es, para las diferentes modalidades de contratos celebrados por los intermediarios de seguros: agentes de seguros exclusivos, agentes de seguros vinculados y corredores de seguros. En relación con estos últimos, el régimen general de determinación de la ley aplicable del Reglamento "Roma I" se aplica, tanto a la relación jurídica del corredor de seguros con el cliente como, en su caso, a la eventual relación jurídica existente entre el corredor de seguros con la entidad aseguradora ${ }^{23}$.

\section{La ley aplicable a los contratos internacionales de seguro: dualidad de regímenes}

25. Los contratos de seguro son objeto de un tratamiento conflictual independiente al de los contratos celebrados por los intermediarios de seguros y al de los contratos de reaseguro. Como es sabido, a

\footnotetext{
${ }^{22}$ Los conceptos autónomos, contenidos en el Reglamento "Roma I", constituyen una manifestación evidente del principio de conciliación del ordenamiento jurídico de la Unión Europea.

${ }^{23}$ En relación con la problemática, de la ley aplicable a los contratos internacionales de intermediación de seguros y de reaseguros privados, vid., por todos, H., Aguilar Grieder, "La mediación de seguros privados desde la perspectiva del derecho internacional privado español: problemas de ley aplicable", en M.R., Quintáns EIRAS, Estudios sobre Mediación de Seguros Privados, Navarra, Thomson Reuters, Aranzadi, 2013, pp. 677-715, especialmente pp. 689-712; así como M., SABIDo RodRÍGUEZ, "La mediación en el contrato de reaseguro: algunas cuestiones de Derecho internacional privado", ibid., pp. 717-742.
} 
través de los contratos de seguro se materializa la relación jurídica existente entre la entidad aseguradora y el cliente $o$ asegurado.

El Reglamento "Roma I" ha modificado sustancialmente el régimen conflictual de los contratos de seguro con respecto a su antecesor directo (el Convenio de Roma). En concreto, el art. 7 del Reglamento contiene una norma de conflicto específica para los contratos de seguro, la cual aparece encuadrada en el marco del régimen especial de Derecho aplicable ${ }^{24}$. De conformidad con el anteriormente mentado Considerando 23 del Reglamento "Roma I", el objetivo prioritario del señalado régimen especial, de determinación de la ley aplicable, es proteger a la parte débil de la relación contractual por medio de normas de conflicto más favorables a sus intereses que las que conforman el régimen general de Derecho aplicable (arts. 3 y 4 del Reglamento).

26. El interés fundamental que subyace detrás del art. 7 del Reglamento "Roma I" es su finalidad tuitiva $^{25}$, ya que el susodicho precepto responde, claramente, a un interés de protección del asegurado o tomador del seguro. Tal como pone de relieve el Considerando 32 del Reglamento "Roma I", al igual que acontece con los contratos de transporte, como consecuencia de las características especiales que presentan los contratos de seguro, deberá garantizarse un nivel adecuado de protección a los titulares de las pólizas mediante normas específicas y, por consiguiente, "el art. 6 no debe aplicarse en el contexto" 26 de este contrato específico. Dicha finalidad tuitiva es predicable, con carácter general, de los contratos de seguro, aunque no todos ellos precisan del mismo nivel de protección.

27. Detrás del art. 7 del Reglamento "Roma I" subyace, igualmente, la idea de no modificar sustancialmente el régimen previsto en las Directivas comunitarias sobre seguros, ya que, de facto, el contenido de dichas Directivas ha sido incorporado en el propio articulado del Reglamento, en concreto, en su art. 7. A mi modo de ver, el legislador europeo ha apostado por la comodidad, adoptando una actitud excesivamente práctica, trasladando sin espíritu crítico las normas de conflicto existentes en este sector, contenidas en las Directivas sobre seguros de la Unión Europea, al marco del art. 7 del Reglamento "Roma I". En mi opinión, se debería de haber aprovechado la oportunidad para reemplazar las referidas normas de conflicto por otras de una calidad técnica superior a la par que menos complejas; lo cual hubiese facilitado, en gran medida, su correcta aplicación por el juez u operador jurídico; que es, en definitiva, lo que se ha de procurar, y más en uno de los sectores más complejos de la contratación internacional en el que, además, coexisten diferentes modalidades contractuales.

28. Al margen de lo señalado, tal como he puesto de manifiesto en un apartado anterior del presente trabajo, a diferencia de lo que acontecía en el marco del Convenio de Roma de 1980, los contratos de seguro, con la excepción aislada tan específica anteriormente comentada, quedan incluidos dentro del ámbito de aplicación material del Reglamento "Roma I". Sin embargo, no todos los contratos de seguro quedan incluidos dentro del ámbito del régimen especial de Derecho aplicable contenido en el art. 7 del Reglamento "Roma I", esto es, de la norma de conflicto especial prevista por el legislador europeo para los contratos de seguro.

De este modo, en relación con los contratos internacionales de seguro, a efectos conflictuales, es preciso distinguir dos situaciones diferenciadas, ya que, al igual que acontece con los contratos internacionales de consumo, algunos de ellos quedan sujetos al régimen general de Derecho aplicable consagrado por el legislador europeo en los arts. 3 y 4 del Reglamento "Roma I"; mientras que otros contratos de seguro quedan sometidos al art. 7 del Reglamento. Esta dicotomía conflictual conlleva un

${ }^{24}$ Tal como se desprende del apartado $4^{\circ}$ del art. 1 del Reglamento "Roma I", en el marco del art. 7 del Reglamento, el término "Estado miembro" designará a todos los Estados miembros de la Unión Europea, incluyendo a Dinamarca.

${ }^{25}$ En relación con los intereses subyacentes detrás del régimen especial de Derecho aplicable contenido en el art. 7 del Reglamento "Roma I", algunos de los cuales tienen su origen en cargas anteriores del legislador europeo, vid., por ejemplo, H., Agullar Grieder, Pilares Fundamentales del Derecho internacional privado europeo, Servicio de Publicaciones de la Universidad de Huelva, 2018, pp. 193-196.

${ }^{26}$ Como puede deducirse de lo señalado, el legislador europeo no considera apropiado aplicar, a los contratos de seguro, la norma de conflicto especial, prevista para los contratos de consumo, en el art. 6 del Reglamento "Roma I". 
notable plus de complejidad en la práctica internacional y, por consiguiente, dificulta la aplicación, a los jueces u operadores jurídicos, de las correspondientes normas conflictuales.

29. La solución conflictual difiere en función del tipo de contrato internacional de seguro ante el cual nos encontremos, que es muy variada. En concreto, el régimen de Derecho aplicable del Reglamento "Roma I", así como la norma de conflicto aplicable, son susceptibles de variar en función del tipo de contrato de seguro de que se trate y, al menos a priori, del nivel de protección requerido en cada una de sus modalidades ${ }^{27}$. No obstante, como vamos a poner de manifiesto en las líneas siguientes, esto último no ha sido tenido en cuenta por el legislador europeo en todos los casos.

30. En concreto, quedan sujetos al régimen especial de Derecho aplicable, consagrado por el art. 7 del Reglamento "Roma I", los siguientes contratos internacionales de seguro.

Por un lado, todos los todos los contratos de seguro que cubran grandes riesgos, para los cuales el legislador europeo ha consagrado una norma de conflicto especial en el apartado 2 del art. 7 del Reglamento. Dicha norma de conflicto incrementa la autonomía conflictual, para esta modalidad de contrato de seguro, al remitirse al art. 3 del Reglamento sin establecer limitaciones adicionales a la autonomía conflictual de las partes. Desde mi punto de vista, ello es apropiado, ya que en este tipo de contrato de seguro se presume que no existe un desequilibrio en la posición negocial de las partes, esto es, que no existe una parte débil de la relación litigiosa, por lo que limitaciones adicionales a la autonomía conflictual de las partes carecen de sentido.

Teniendo en cuenta lo señalado, me parece digno de crítica que el legislador europeo haya sometido esta modalidad de contrato de seguro al régimen especial de ley aplicable del Reglamento "Roma I", por no existir una parte del contrato especialmente necesitada de protección y por responder el régimen especial de Derecho aplicable, fundamentalmente, a una finalidad tuitiva. En concreto, tal como reconoce el propio legislador europeo, detrás del art. 7 del Reglamento "Roma I" subyace, muy especialmente, una finalidad de protección del asegurado o tomador del seguro. A mi modo de ver, desde una perspectiva de lege ferenda, hubiese resultado más acertado someter esta modalidad contractual al régimen general de Derecho aplicable y consagrar en el art. 4.1 del Reglamento "Roma I", para los supuestos en los cuales no haya elección de ley por las partes en los términos previstos en el art. 3 del Reglamento, una norma de conflicto especial que tuviese en cuenta la especificidad de este tipo de contrato de seguro.

En defecto de elección de ley por las partes de conformidad con el art. 3 del Reglamento "Roma I", el contrato de seguro que cubra un gran riesgo se regirá "por la ley del país en el que el asegurador tenga su residencia habitual". Teniendo en cuenta que el legislador europeo ha encuadrado los contratos de seguro, que cubren grandes riesgos, dentro del régimen especial de Derecho aplicable, llama la atención que el precepto se centre, para determinar la ley objetivamente aplicable de esta modalidad de contrato de seguro, en el asegurador, esto es, en la parte supuestamente fuerte de los contratos de seguro.

\footnotetext{
${ }^{27}$ Un detenido análisis de la problemática de los contratos de seguro, desde el enfoque del Derecho aplicable, puede encontrarse en C., CaAmiña Domínguez, "Los contratos de seguro del art. 7 del Reglamento Roma I", CDT, 2009, vol. I, núm. 2, pp. 30-51; C. CAAmiña Domínguez, "Contratos internacionales (VIII). Contrato internacional de seguro", en A.L. CALVO Caravaca/J. Carrascosa González (Directores), Derecho del Comercio Internacional, Colex, Madrid, 2012, pp. 1053-1085, pp. 1071-1085; C. CAamiña Domínguez/J.M. Almudí Cid, "El contrato internacional de seguro", en M. IzQuierdo Tolsada, Contratos civiles, mercantiles, públicos, laborales e internacionales, con sus implicaciones tributarias, Tomo VII, Los contratos internacionales (II), Thomson Reuters, Aranzadi, Pamplona, 2014, pp. 581-635, pp. 603-626; V. Fuentes CAMACHO, "Los contratos internacionales de seguro antes y a partir del Reglamento Roma I", Revista Española de Seguros, El nuevo régimen comunitario de los contratos internacionales de seguro, 2009, núm. 140, pp. 617-634; U. Peter GruBer, "Insurance contracts", en F. Ferrari/S. LeIble, Rome I Regulation. The Law Applicable to Contractual Obligations in Europe, Sellier, European law publishers, Munich, 2009, pp. 109-128; H. HeIss, "Insurance contracts in 'Rome I': Another Recent Failure of the European Legislature", en E. CASHIN RITAINE/A. BonOMI, Le nouveau règlement européen "Rome I" relative à la loi applicable aux obligations contractuelles, Schulthess, Publications de l'Institut suisse de droit comparé, Genève, Zürich, Bâle, 2008, pp. 97-119; así como A. Staudinger, “Internationales Versicherungsvertragsrecht - (k)ein Thema für Rom I?”, en F. Ferrari/S. LeIBLE, Ein neues Internationales Vertragsrecht für Europa, Studien zum Internationalen Privat- und Verfahrensrecht, Band 10, Gottmadingen, Jenaer Wissenschaftliche Verlagsgesellschaft, 2007, pp. 235-243.
} 
No obstante, ello tampoco es tan grave si tenemos en cuenta que, precisamente en este tipo de contrato de seguro, no existe un desequilibrio en la posición negocial de las partes.

El legislador europeo ofrece un concepto autónomo, derivado de una Directiva europea de seguros, de lo que ha de entenderse por "contrato de seguro que cubra un gran riesgo" 28 . A mi modo de ver, dicha actitud del legislador europeo ha de ser aplaudida, ya que tal remisión constituye una clara manifestación del principio de conciliación del ordenamiento jurídico de la Unión Europea.

Al margen de lo señalado, el contrato de seguro que cubre grandes riesgos es el único tipo de contrato de seguro en el que no influye, a los efectos de la solución conflictual, el lugar de localización del riesgo cubierto ${ }^{29}$. De este modo, el tratamiento conflictual de la susodicha categoría de contrato de seguro no varía en función de si el riesgo cubierto se encuentra localizado en un Estado miembro de la Unión Europea o en un Estado tercero; lo cual nos parece acertado. Desde mi punto de vista, ello habría de proyectarse a las restantes modalidades de contratos de seguro.

Otra peculiaridad de esta modalidad de contrato de seguro es que el legislador europeo ha previsto sólo para este tipo contractual una cláusula de excepción de alcance particular. Esta cláusula de excepción es muy específica, ya que sólo es operativa en relación con esta categoría contractual. El legislador europeo no ha consagrado ninguna cláusula de excepción para los restantes contratos de seguro. La cláusula de excepción de alcance particular, prevista por el apartado $2^{\circ}$ del art. 7 del Reglamento "Roma I" para los contratos de seguro que cubran un gran riesgo, es prácticamente idéntica a la contemplada en el art. 5.3 del Reglamento para los contratos de transporte (tanto de mercancías como de pasajeros): si "del conjunto de circunstancias se desprende que el contrato (se está refiriendo únicamente al contrato de seguro que cubra un gran riesgo) presenta vínculos manifiestamente más estrechos con otro país, se aplicará la ley de ese otro país"30, es decir, la ley del país con el que presente los vínculos más estrechos. Por medio del término "manifiestamente", el legislador europeo ha querido recalcar el carácter excepcional de la cláusula de escape.

A mi modo de ver, estas son las peculiaridades más llamativas y de mayor repercusión práctica, en el ámbito del Reglamento "Roma I", de los contratos de seguro que cubren grandes riesgos.

31. Por otro lado, tal como se desprende del apartado $1^{\circ}$ del art. 7 del Reglamento "Roma I", quedan incluidos dentro del ámbito de aplicación del régimen especial de Derecho aplicable, contenido en el art. 7 del Reglamento, los contratos de seguro que cubran riesgos localizados en el territorio de los Estados miembros de la Unión Europea; salvo que se trate, como hemos señalado en las líneas anteriores, de un contrato de seguro que cubra un gran riesgo. El legislador europeo ha previsto una norma de conflicto especial, en el apartado 3 del art. 7 del Reglamento "Roma I", para los contratos de seguro que cubran riesgos localizados en el área de la Unión Europea.

El art. 7 del Reglamento "Roma I", en su apartado 5, resuelve un problema susceptible de presentarse en la práctica: cuando un contrato de seguro, que no cubra un gran riesgo, cubra riesgos situados en más de un Estado miembro. En tal caso, el legislador europeo ha considerado que "el contrato se considerará constituido por diversos contratos, cada uno de los cuales se refiere únicamente a un Estado miembro". Esta puntualización también se aplica a los contratos de seguro obligatorios.

En relación con la modalidad de contrato de seguro a la que nos estamos refiriendo (los que cubren un riesgo localizado en un Estado miembro de la Unión Europea), el legislador europeo ha consagrado, en el apartado $3^{\circ}$ del art. 7 del Reglamento "Roma I", una autonomía conflictual limitada en cuanto a las leyes estatales susceptibles de elección; las cuales están estrechamente vinculadas con el contrato de seguro en cuestión (ley del Estado miembro en el cual se localice el riesgo, ley del país en el cual el tomador del seguro tenga su residencia habitual, etc. $)^{31}$.

\footnotetext{
${ }^{28}$ Vid. la remisión llevada a cabo en el apartado 2 del art. 7 del Reglamento "Roma I".

${ }^{29}$ Tal como pone de manifiesto el apartado 1 del art. 7 del Reglamento "Roma I", el presente artículo se aplicará a los contratos a que se refiere el apartado 2, "independientemente de que el riesgo que cubran se localice o no en un Estado miembro".

${ }^{30}$ La cursiva es nuestra.

${ }^{31}$ Por lo que a dichas leyes se refiere, vid. el apartado 3 del art. 7 del Reglamento "Roma I". En alguno de los supuestos contemplados por el susodicho apartado, "si los Estados miembros a los que dichos apartados se refieren (a, b o e) conceden mayor libertad de elección en cuanto a la ley aplicable al contrato de seguro, las partes podrán hacer uso de tal libertad".
} 
En defecto de elección de ley por las partes en los términos que acabamos de señalar, el contrato de seguro, relativo a un riesgo localizado en un Estado miembro de la Unión Europea, se regirá por la ley del "Estado miembro en el que se localice el riesgo en el momento de la celebración del contrato". Por medio de esta última coletilla del art. 7.3 del Reglamento "Roma I", el legislador europeo resuelve el problema del conflicto móvil, al especificar el momento en el cual ha de concretarse el punto de conexión utilizado por la norma de conflicto aplicable en defecto de elección de ley: el de la celebración del correspondiente contrato de seguro.

32. Y, por último, también quedan incluidos dentro del ámbito del régimen especial de Derecho aplicable, contenido en el art. 7 del Reglamento "Roma I", los contratos de seguro obligatorio, esto es, aquellos contratos de seguros que cubran riesgos para los que un Estado miembro imponga la obligación de suscribir un seguro. El art. 7 del Reglamento "Roma I" consagra en su apartado 4, para dicha modalidad de contrato de seguro, determinadas normas adicionales.

33. De lo señalado en las líneas anteriores se desprende que no todos los contratos de seguro quedan incluidos dentro del ámbito de aplicación del art. 7 del Reglamento "Roma I". Ello implica que los contratos de seguro, excluidos de dicho régimen especial, hayan de quedar sometidos al régimen general de Derecho aplicable del Reglamento, esto es, a sus arts. 3 y 4 . Tal como se desprende del apartado $1^{\circ}$ del art. 7 del Reglamento "Roma I", los contratos de seguro que cubran riesgos localizados en un Estado no miembro de la Unión Europea, salvo que cubran un gran riesgo, quedarán sujetos al régimen general de Derecho aplicable.

Teniendo en cuenta lo señalado, nos interesa saber qué ocurre en los supuestos híbridos, esto es, cuando "un contrato de seguro que no cubre un gran riesgo cubra varios riesgos de los que uno como mínimo está situado en un Estado miembro y uno como mínimo está situado en un tercer país". Dicha problemática, susceptible de plantearse en la práctica internacional, la resuelve el legislador europeo en el Considerando 33 del Reglamento "Roma I". En tal caso, "las disposiciones especiales del presente Reglamento relativas a los contratos de seguro únicamente deben aplicarse al riesgo o riesgos en el Estado miembro o en los Estados miembros de que se trata". Dicha aclaración es clave, ya que, como se ha podido comprobar en el presente apartado del trabajo, el criterio del lugar de localización del riesgo cubierto, en el área de la Unión Europea o en un tercer Estado, es fundamental a los efectos del tratamiento conflictual del contrato internacional de seguro.

\section{A modo de conclusiones}

34. De los señalado en los apartados anteriores se desprende una acentuada especificidad o especialización, en las soluciones conflictuales, de los contratos internacionales intervinientes en el mercado asegurador. Ello está en sintonía con la tendencia general del Derecho internacional privado de la Unión Europea en materia contractual ${ }^{32}$. Dicha tendencia va encaminada, con carácter general, a obtener una mayor previsibilidad; lo cual, a mi modo de ver, es más que discutible que se haya logrado en materia de seguros, teniendo en cuenta la extrema complejidad de su regulación y su deficiente calidad técnica.

35. Al margen de lo señalado, nos parece digno de crítica, y en la actualidad totalmente injustificable, que los contratos internacionales de seguro, que cubran riesgos localizados en un Estado tercero, salvo que cubran "un gran riesgo", reciban el mismo tratamiento y solución conflictual que los contratos internacionales de reaseguro y que los contratos internacionales de intermediación de seguros privados, es decir, que los contratos de agencia de seguros, que los contratos de corretaje o de mediación de seguros y que los restantes contratos internacionales suscritos por los intermediarios de seguros.

${ }^{32}$ Por lo que a dicha tendencia se refiere, vid., muy especialmente, H., Aguilar Grieder, "Desafíos y tendencias en el actual Derecho internacional privado europeo de los contratos", CDT, 2012, vol. 4, núm. 2, pp. 23-48. 
36. Como hemos podido comprobar en el apartado anterior, hay contratos de seguro excluidos del ámbito de aplicación del art. 7 del Reglamento "Roma I", por la mera localización del riesgo en un Estado tercero, necesitados de protección; y contratos incluidos en el régimen especial del art. 7 del Reglamento "Roma I" en los que no existe tal necesidad de protección, como es el caso del seguro que cubre grandes riesgos. A mi modo de ver, ello conlleva una desnaturalización del régimen especial de Derecho aplicable del Reglamento, cuya finalidad, como sabemos, es fundamentalmente tuitiva.

\section{Valoración de la coherencia del Derecho de la Unión Europea en el ámbito de la protección del consumidor de seguros}

37. Teniendo en cuenta la inmensa repercusión, a efectos conflictuales, del criterio del lugar de localización del riesgo cubierto, es básico que el legislador europeo nos aclare cuál es, a los efectos del Reglamento "Roma I", el lugar de localización del riesgo cubierto. Respondiendo a esta necesidad, el legislador europeo concreta, en el apartado 6 del art. 7 del Reglamento "Roma I", a los efectos del referido precepto, que el país en el que se localiza el riesgo habrá de determinarse de conformidad con lo previsto en las Directivas de la Unión Europea sobre seguros. El recurso, en el marco del Reglamento "Roma I", a un concepto autónomo supone una manifestación evidente del principio de conciliación del ordenamiento jurídico de la Unión Europea. De este modo, los instrumentos normativos de la Unión Europea, implicados en este sector jurídico, parten de un mismo concepto. A mi modo de ver, es un acierto que el legislador europeo haya consagrado un concepto uniforme, válido para todos los Estados miembros de la Unión Europea, en relación con una cuestión tan relevante a efectos de la determinación de la ley aplicable a los contratos internacionales de seguro. Ello denota, sin lugar a dudas, una coherencia, en el seno del ordenamiento jurídico de la Unión Europea, en lo que respecta a conceptos clave.

38. Sin embargo, tal coherencia, demandada por el principio de conciliación del ordenamiento jurídico de la Unión Europea, no existe desde otro punto de vista, en cuanto que, en relación con los susodichos contratos internacionales de seguro, por la mera localización del riesgo cubierto en un tercer Estado, el Reglamento "Roma I" no tiene en cuenta el nivel de protección requerido por el tipo de contrato de seguro de que se trate. Desde este enfoque, no existe sintonía entre el Reglamento "Roma I" y las Directivas europeas de seguros, cuyas disposiciones materiales responden a una finalidad tuitiva, de protección del asegurado o tomador del seguro. A mi modo de ver, dicho déficit o falta de coherencia es merecedor de una crítica severa. La exclusión, del régimen especial de Derecho aplicable contenido en el art. 7 del Reglamento "Roma I", de los contratos internacionales de seguro que cubran riesgos localizados en un Estado no miembro de la Unión Europea, trae causa del régimen existente en el marco del antecesor del Reglamento: el Convenio de Roma de 1980. En el ámbito de dicho Convenio, los susodichos contratos internacionales de seguro eran objeto de regulación en el plano conflictual por Directivas europeas, lo cual justificaba la mencionada exclusión. Pero en el marco del Reglamento "Roma I", la justificación de dicha exclusión carece de sentido, de razón de ser, ya que las normas de conflicto de las Directivas de la Unión Europea sobre seguros han sido trasladadas, por el legislador europeo, al art. 7 del Reglamento "Roma I".

39. Al margen de lo señalado, es preciso valorar la coherencia o coordinación de la Directiva (UE) 2016/97 sobre la distribución de seguros con las normas de conflicto, del Reglamento "Roma I", aplicables a los contratos internacionales intervinientes en el mercado asegurador. Para ello es necesario analizar el alcance de las novedades incorporadas por la señalada Directiva con respecto a su antecesora directa (la Directiva 2002/92/CE). Como anteriormente adelantamos, la Directiva de 2016 goza de una enorme repercusión práctica en lo concerniente al sector de la distribución en la contratación de seguros.

La Directiva europea 2002/92/CE sobre la mediación en los seguros fue objeto de una viva controversia doctrinal. Como consecuencia de las críticas suscitadas por la misma, las instituciones europeas iniciaron, en aras de su modificación, un proceso de reforma de la Directiva 2002/92/CE; que se materia- 
lizó en la Propuesta de Directiva del Parlamento Europeo y del Consejo sobre la mediación en los seguros (Refundición) $^{33}$. La finalidad básica de la referida Propuesta de Directiva era incrementar notablemente su ámbito de aplicación, y ello en aras de aumentar la protección de los clientes, esto es, de los consumidores de seguros $^{34}$. La reforma europea pretendía, en última instancia, una ampliación y reformulación del concepto de mediación, lo cual implica un tránsito de la mediación a la distribución de seguros; siendo éste, como es sabido, el título de la actual Directiva europea. En aras de ofrecer una mayor protección al asegurado o tomador del seguro, las instituciones europeas tenían previsto acometer diversas reformas: entre ellas, ofrecer una mayor información y asesoramiento al asegurado o tomador del seguro; evitar o minimizar el conflicto de intereses subyacente a este tipo de contratación; así como modificar el sistema de remuneración (especialmente en lo que atañe a la retribución del corredor de seguros) ${ }^{35}$.

En relación con el ámbito de aplicación material de la antecesora de la Directiva actualmente vigente (la Directiva 2002/92/CE), es preciso señalar que la misma regulaba la actividad profesional de aquellas personas o instituciones que distribuyen los productos de seguros o, en su caso, de reaseguros, a cambio de una remuneración. La referida Directiva se aplicaba, pues, tanto a personas físicas como jurídicas, siempre y cuando la actividad de mediación de seguros realizada por dichas personas no consistiese en una actividad meramente accesoria o en facilitar una simple información general sobre los productos de seguros o, en su caso, de reaseguros. En cualquier caso, la Directiva anteriormente vigente de mediación de seguros no cubría aquellos supuestos en los cuales la actividad la realizaba, o bien, una empresa de seguros (o, en su caso, de reaseguros), o bien, un empleado de las mismas.

Sin embargo, tal como ya figuraba en la Propuesta de Directiva sobre la mediación en los seguros a la que nos acabamos de referir, la Directiva (UE) 2016/97 sobre la distribución de seguros, en aras de incrementar notablemente la protección del cliente o asegurado, incluye los susodichos supuestos dentro de su ámbito de aplicación material. De este modo, la Directiva de 2016 (tal como tenía previsto la citada Propuesta de Directiva de mediación de seguros), como consecuencia de estar enfocada a la protección del consumidor de seguros, extiende su ámbito de aplicación a la actividad aseguradora directa, ya que, de este modo, consigue proyectar los nuevos parámetros de protección del cliente, que la misma incorpora, a la actuación de la entidad aseguradora; tratando de alcanzar, de este modo, un mayor nivel de protección del asegurado que la anteriormente vigente Directiva de 2002 sobre la mediación en los seguros. La notable ampliación de su ámbito de aplicación, así como el incremento del nivel de protección del consumidor de seguros, son, sin lugar a dudas, las novedades más esperadas y de mayor repercusión práctica de la Directiva europea 2016/97 sobre la distribución de seguros ${ }^{36}$. Como hemos señalado anteriormente, estas dos novedades se encuentran estrechamente interrelacionadas entre sí.

Como ya comentamos en un apartado anterior del presente trabajo, la Directiva (UE) 2016/97 sobre la distribución de seguros ha sido objeto de transposición a los ordenamientos jurídicos internos de todos los Estados miembros de la Unión Europea y, en concreto, al ordenamiento jurídico español a través, no de la proyectada Ley de distribución de seguros y reaseguros privados (la cual estaba previsto que entrase en vigor a principios de 2018) ${ }^{37}$, sino del anteriormente mentado Real Decreto-Ley 3/2020,

${ }^{33}$ La señalada Propuesta de Directiva fue presentada en Bruselas, por la Comisión Europea, el 3 de julio de 2012: COM (2012) 360 final. Vid., igualmente, el Dictamen del Comité Económico y Social Europeo sobre la Propuesta de Directiva del Parlamento Europeo y del Consejo relativa a la mediación en los seguros (refundición): DOUE, de 15 de febrero de 2013, núm. C 44/95.

${ }^{34}$ Vid. la Exposición de Motivos de la Propuesta de Directiva, en concreto, la parte relativa al "Contexto de la Propuesta". En relación con las novedades de dicha Propuesta, vid., por ejemplo, C., DíAz LLAvona, "Propuesta de revisión de la Directiva 2002/92/CE, de mediación de seguros. Antecedentes, principales novedades y aspectos discutibles", en los números monográficos editados por la RES con ocasión de los “25 años de Planes de pensiones", 2012, núms. 150-151, abril-septiembre, pp. 245-262.

${ }_{35}$ En relación con el contexto de la referida reforma europea de la mediación a la distribución de seguros, vid., muy especialmente, M.R., Quintáns Eiras, "Reforma de la distribución de seguros en la Unión Europea”, en J., Bataller Grau/ M.R. Quintáns Eiras/A.B., Veiga Copo (Directores), La reforma del Derecho del seguro, Navarra, Thomson Reuters, Aranzadi, 2015, pp. 557-574.

${ }^{36}$ Un exhaustivo análisis de las principales novedades de la referida Directiva europea, así como de la repercusión de las mismas, puede encontrarse en M.R., Quintáns EIRAS, "De la mediación a la distribución de seguros: la nueva Directiva 2016/1997”, Revista General de Derecho Europeo, 2016, vol. 39, pp. 1-22.

37 Tal como ponía de manifiesto la Disposición final quinta de la referida Ley, relativa a su entrada en vigor, la presente Ley "entrará en vigor el día siguiente al de su publicación en el Boletín Oficial del Estado". 
el cual sustituye a la Ley 26/2006, de 17 de julio, de mediación de seguros y reaseguros privados (en lo sucesivo, Ley 26/2006) ${ }^{38}$. La Ley 26/2006 llevó a cabo, en su momento, la transposición, al ordenamiento jurídico español, de la Directiva europea 2002/92/CE sobre la mediación en los seguros; a la cual ha sustituido la actualmente vigente Directiva (UE) 2016/97 sobre la distribución de seguros.

El Real Decreto-Ley 3/2020, al igual que el Proyecto de Ley de distribución de seguros y reaseguros privados, distingue entre mediadores de seguros (o de reaseguros) y distribuidores de seguros (o de reaseguros). Tal como se desprende del articulado del referido Real Decreto-Ley, y de la Directiva cuya transposición lleva a cabo, la actividad de distribución de seguros puede ser realizada por las entidades aseguradoras, por los agentes de seguros, por los operadores de banca-seguros, así como por los corredores de seguros. El extenso ámbito de aplicación del Real Decreto-Ley 3/2020 está en sintonía con una de las principales novedades de la Directiva (UE) 2016/97 sobre la distribución de seguros (cuya transposición ha llevado a efecto): extender considerablemente el ámbito de aplicación material de la Directiva 2002/92/CE, abarcando también la actividad aseguradora directa, y ello en aras de aumentar el nivel de protección de los consumidores de seguros al proyectar los nuevos parámetros de protección del cliente o asegurado, que la Directiva 2016/97 incorpora, a la actuación de la entidad aseguradora. Al margen de lo señalado, la Directiva (UE) 2016/97 sobre la distribución de seguros, al incluir también dentro de su ámbito de aplicación la actividad aseguradora directa, consigue alcanzar, aunque sea de un modo indirecto, otro objetivo fundamental: homogeneizar las condiciones de competencia en el seno del mercado interior. Por lo tanto, detrás de la Directiva de 2016 sobre la distribución de seguros, al igual que acontece con las restantes Directivas elaboradas por las instituciones europeas para determinados sectores de la contratación, subyace un doble objetivo: la protección de la parte débil de la relación litigiosa (asegurado o tomador del seguro) y la protección del mercado interior.

A mi modo de ver, ello no está en sintonía con la dispersión conflictual existente, en el marco del Reglamento "Roma I", en el seno del mercado asegurador. Tal como hemos apreciado en el apartado anterior del presente trabajo, los contratos internacionales intervinientes en el mercado asegurador reciben un tratamiento conflictual diferenciado, lo cual puede acarrear que resulten aplicables leyes estatales basadas en principios diferentes (en cuanto al nivel de protección del asegurado o tomador del seguro, requisitos impuestos a los intermediarios de seguros para poder llevar a cabo su actividad profesional, etc.). Tal problemática se acentúa si tenemos en cuenta que, de conformidad con el art. 2 del Reglamento "Roma I", el mismo goza de un ámbito de aplicación espacial universal (es decir, es erga omnes) y la ley estatal aplicable a los contratos internacionales, determinada por la norma de conflicto que resulte aplicable, puede ser tanto la de un Estado miembro de la Unión Europea (en cuyo caso se cumplirían los parámetros de protección fijados por la Directiva europea sobre la distribución de seguros) como la de un Estado tercero (la cual puede basarse en principios muy diferentes a los que subyacen detrás de la Directiva 2016/97 sobre la distribución de seguros).

De este modo, la dispersión conflictual, existente en el seno del mercado asegurador, puede comprometer la protección del cliente o consumidor de seguros, así como la del mercado interior; en la medida en que ello es susceptible de provocar evidentes distorsiones de competencia en el seno del mercado europeo. En aras de evitar estos efectos perjudiciales, para el asegurado o tomador del seguro y para el mercado interior, es imprescindible que el consumidor de seguros goce del nivel de protección fijado por la Directiva europea sobre la distribución de seguros, y ello con independencia de que la lex contractus sea la de un Estado miembro de la Unión Europea o la de un tercer Estado.

En este contexto, nos parece acertado sacar a colación la polémica sentencia del TJCE de 9 de noviembre de 2000 (asunto Ingmar), la cual, aunque versa sobre un contrato internacional de agencia comercial, ha tenido una enorme repercusión en el ámbito de la contratación internacional por todas sus implicaciones. El TJCE puso de manifiesto en dicha sentencia que, los objetivos perseguidos por los arts. 17-19 de la Directiva 86/653/CE del Consejo, de 18 de diciembre de 1986, relativa a la coordina-

${ }^{38}$ BOE, de 18 de julio de 2006, núm. 170. Un pormenorizado análisis del referido cuerpo legal puede encontrarse en F.J., Tirado Suárez./M.A., Sartí Martínez, Ley de Mediación en Seguros y Reaseguros Privados, Cizur Menor (Navarra), Aranzadi, 2007; así como en V. Cuñat Edo/J. Bataller Grau, Comentarios a la Ley de Mediación de Seguros y Reaseguros Privados, Cizur Menor, Aranzadi, Navarra, 2007. 
ción de los derechos de los Estados miembros en lo referente a los agentes comerciales independientes ${ }^{39}$, exigen que tales disposiciones sean de aplicación, con independencia de cuál sea la lex contractus, cuando el agente comercial realice su actividad profesional en un Estado miembro de la Unión Europea ${ }^{40}$, con independencia de que el agente comercial esté establecido o no en el área de la Unión Europea. Tal como pone de manifiesto la sentencia Ingmar, el objetivo perseguido por los mencionados preceptos, los cuales constituyen el núcleo duro de la misma, es "proteger, a través de la categoría de los agentes comerciales, la libertad de establecimiento y el juego de una competencia no falseada en el mercado interior" (apartado 24). Según el TJCE, la función que desempeñan las referidas disposiciones de la Directiva de agencia requiere que éstas se apliquen cuando "el agente comercial desempeñe su actividad en el territorio de un Estado miembro, sea cual fuere la ley a la que las partes hayan pretendido someter el contrato" (apartado 25). A nuestro modo de ver, dicho razonamiento es extrapolable al resto de las disposiciones materiales de carácter imperativo, no sólo de la Directiva de agencia comercial de 1986, sino también de la Directiva de 2016 sobre la distribución de seguros.

\section{Mecanismos para la protección del consumidor de seguros y del mercado interior frente a los efectos de la dispersión conflictual}

40. Como anteriormente adelantamos, en el sector asegurador coexisten los textos de Derecho internacional privado con las Directivas europeas del mercado asegurador. En concreto, en sede de ley aplicable, se produce una coexistencia de las disposiciones materiales de carácter imperativo de ciertas Directivas europeas sectoriales (de seguros, de distribución de seguros y subsidiariamente, en el contrato de agencia de seguros, de la Directiva de agencia) y, más en concreto, de sus normas nacionales de transposición, con las normas de conflicto contenidas en el Reglamento "Roma I". Ello plantea complejos problemas de coordinación, los cuales han de resolverse con arreglo al principio de conciliación del ordenamiento jurídico de la Unión Europea.

El Reglamento "Roma I" contiene, por lo que al mercado asegurador se refiere, diversas manifestaciones del principio de conciliación del ordenamiento jurídico de la Unión Europea: entre ellas, el apartado 2j) del art. 1 (al definir un supuesto de contrato de seguro muy específico que queda excluido del ámbito de aplicación material del Reglamento), el apartado 4 del art. 1 (al definir lo que se entiende por "Estado miembro" a los efectos de los arts. 3.4 y 7 del Reglamento), el apartado 2 del art. 7 (al contener un concepto autónomo de "contrato de seguro que cubra un gran riesgo"), así como el apartado 6 del art. 7 (al ofrecer un concepto autónomo de lugar de localización del riesgo). Pero el principio de conciliación del sistema jurídico de la Unión Europea no se materializa exclusivamente en la elaboración por el legislador europeo de conceptos autónomos, sino que va mucho más allá.

La acusada concurrencia normativa, existente en el sector de la distribución de los seguros privados, en el que coexiste el marco normativo general y el específico, habrá de hacerse frente partiendo del conocido principio de conciliación del ordenamiento jurídico de la Unión Europea; el cual proyecta, al ámbito del Derecho de la Unión Europea, la coherencia valorativa que ha de existir, en el marco de los ordenamientos jurídicos estatales, entre su sistema de Derecho internacional privado y el Derecho privado interno del Estado en cuestión. En aras de hacer efectivo el susodicho principio, es necesario encontrar mecanismos o vías que permitan alcanzar una armonía o coherencia de valores entre el Derecho internacional privado de la UE (el Reglamento "Roma I") y el Derecho europeo material, ya que ambos forman parte de un mismo ordenamiento jurídico ${ }^{41}$. Teniendo en cuenta el principio de concilia-

\footnotetext{
${ }^{39}$ DOCE, de 31 de diciembre de 1986, núm. L 382.

${ }^{40}$ En relación con el concreto alcance de la referida sentencia, vid., por todos, H., Aguilar Grieder, La protección del agente en el Derecho comercial europeo, Colex, Madrid, 2007, especialmente pp. 74-80.

${ }^{41}$ Los problemas de delimitación existentes, en relación con la problemática analizada, entre el marco normativo general y el específico y, más en concreto, entre las normas de conflicto del Reglamento "Roma I" y las disposiciones materiales imperativas de la Directiva de distribución de seguros, o en su caso, de la Directiva de agencia comercial, habrán de resolverse partiendo del principio de conciliación del ordenamiento jurídico de la Unión Europea. Por lo que respecta a las normas pertenecientes al sector del Derecho aplicable, la exigencia de la consecución de compatibilidad o de conciliación, en el seno del sistema jurídico
} 
ción del sistema jurídico de la Unión Europea, se ha de tender a la consecución de una "interpretación armoniosa" de los instrumentos europeos aplicables a los contratos, concibiéndolos como un todo o conjunto normativo unitario y coherente, y no como meros compartimentos estancos ni como textos individualmente considerados e independientes entre sí. Los instrumentos europeos (con independencia de que los mismos contengan normas que determinan la ley aplicable, normas de Derecho Procesal Civil Internacional o meras disposiciones materiales) han de estar al servicio de los principios del mercado interior, de sus objetivos; siendo una de sus finalidades principales la de homogenizar las condiciones de competencia en el marco del espacio europeo. En suma, el Reglamento "Roma I", el Reglamento "Bruselas I bis" y el Derecho europeo derivado (dentro del cual destacan las Directivas europeas sectoriales) han de considerarse como instrumentos complementarios ${ }^{42}$.

En relación con los problemas de coordinación o conciliación de las disposiciones materiales de carácter imperativo de la anteriormente mentada Directiva europea sobre la distribución de seguros con el Reglamento "Roma I", es preciso poner de relieve que existen dos mecanismos de conciliación.

41. Por un lado, tenemos la cláusula general de protección del Derecho de la Unión Europea o también denominada cláusula de protección del mercado interior, la cual constituye, a mi modo de ver, el mecanismo prioritario de conciliación de la Directiva (UE) 2016/97 sobre la distribución de seguros con el Reglamento "Roma I". Dicha cláusula general, que ha sido consagrada por el apartado 4 del art. 3 del Reglamento, es considerada como una de las principales novedades del mismo. Como es sabido, la susodicha cláusula únicamente opera en el marco del régimen general de Derecho aplicable del Reglamento; por lo que sólo es susceptible de operar en relación con los contratos de reaseguro y en los contratos de intermediación de seguros (en todas sus modalidades); pero no en los contratos de seguro, ya que para la operatividad de la mencionada cláusula general es imprescindible, además de haber elegido las partes la ley de un tercer Estado, que todos los elementos del contrato internacional estén vinculados al territorio o espacio de la Unión Europea, y en los contratos de seguro que cubren riesgos localizados en un Estado no miembro de la Unión Europea, que son los únicos contratos de seguro que quedan sujetos al régimen general de Derecho aplicable (salvo que cubran un gran riesgo [ya que estos últimos siempre quedan sometidos al art. 7 del Reglamento]), un elemento relevante ("pertinente" según el Reglamento) del contrato está conectado a un tercer Estado, por lo que no puede operar dicha cláusula.

42. En relación con los contratos de seguro, únicamente son susceptibles de intervenir, en aras de alcanzar la ansiada conciliación de la Directiva sobre la distribución de seguros con el Reglamento "Roma I", las normas materiales internacionalmente imperativas, en concreto, las del ordenamiento jurídico del foro. Las "leyes de policía", que aparecen reguladas en el art. 9 del Reglamento, son susceptibles de operar en todos los contratos internacionales intervinientes en el mercado asegurador (contratos de reaseguro, contratos de intermediación de seguros y contratos de seguro), ya que las leyes de policía, aunque a mi modo de ver constituyen un mecanismo subsidiario de conciliación de las Directivas europeas sectoriales con el Reglamento "Roma I" (ya que, de concurrir los presupuestos de la mentada cláusula general se ha de otorgar primacía a la misma), ofrecen una protección menos parcial, más completa, que la referida cláusula general en la medida en que son susceptibles de intervenir tanto en el marco del régimen general de Derecho aplicable (tanto en relación con el art. 3 como cuando resulte aplicable el art. 4) como del régimen especial; por lo que cubren la laguna anterior en los casos en que no pueda intervenir la cláusula general de protección del Derecho de la Unión Europea. Desde mi punto de vista, el carácter excesivamente restrictivo de la definición de "ley de policía", contenida

comunitario, fue expresamente puesta de manifiesto por el apartado 51c) del denominado Plan de Acción de Viena del Consejo y la Comisión, el cual fue aprobado por el Consejo en el año 1998 (DOCE, de 23 de enero de 1999, núm. C 19/1).

${ }^{42}$ En relación con la necesidad de conciliar o armonizar los referidos cuerpos normativos de la Unión Europea, vid., más ampliamente, H., Aguilar Grieder, "La voluntad de conciliación con las Directivas comunitarias protectoras en la Propuesta de Reglamento 'Roma I'”, en A.L., Calvo Caravaca/E., Castellanos Ruiz (Dirs.), La Unión Europea ante el Derecho de la globalización, Madrid, Colex, 2008, pp. 45-60, especialmente pp. 45-53. 
en el apartado 1 del art. 9 del Reglamento, no supone un obstáculo a su eventual intervención en el mercado asegurador, ya que la mentada Directiva sobre la distribución de seguros, al igual que las Directivas europeas de seguros y que la Directiva de agencia comercial, presenta dos finalidades: por un lado, favorecer el correcto funcionamiento del mercado interior y, por otro lado, la protección de la parte débil de la relación litigiosa. 